Original Article

\title{
Clinical measures as valid predictors and discriminators of the level of community ambulation of hemiparetic stroke survivors
}

GyuChang Lee, PT, PhD ${ }^{1)}$, SeungHeon An, PT, PhD ${ }^{2)}$, YunBok Lee, RN, PhD ${ }^{3)}$, DONG-SiK PARK, MD, $\left.\mathrm{PhD}^{4}\right)^{*}$

1) Department of Physical Therapy, College of Natural Sciences, Kyungnam University, Republic of Korea

2) Department of Physical Therapy, National Rehabilitation Center, Republic of Korea

3) Department of Nurse, Dongseo University, Republic of Korea

4) Department of Rehabilitation Medicine, Kangdong Sacred Heart Hospital, Hallym University College of Medicine: 445 Gil-dong, Gangdong-gu, Seoul 134-701, Republic of Korea

\begin{abstract}
Purpose] To investigate clinical measures as valid predictors and discriminators of the level of community ambulation of hemiparetic stroke survivors. [Subjects and Methods] Seventy-five hemiparetic stroke patients were separated into a community ambulation group $(>0.8 \mathrm{~m} / \mathrm{s})$ and a limited community ambulation group $(0.4-0.8 \mathrm{~m} / \mathrm{s})$. The dorsiflexor strength of the affected side, Sit to Stand (STS) test, Timed Up \& Go (TUG) test, Berg Balance Scale (BBS), Fugl-Meyer Assessment (FMA), Falls Efficacy Scale (FES), 2-min step test (2mST), and 6-min walk test $(6 \mathrm{mWT})$ were used for evaluation. The discriminative powers of the tests and measures were investigated using the receiver-operating characteristic (ROC) curve, and odd ratios were calculated to predict the level of community ambulation. [Results] The cutoff values for predicting the level of community ambulation $(>0.8$ $\mathrm{m} / \mathrm{s}$ ) were $<14.77 \mathrm{~s}$ for TUG, $<12.6 \mathrm{~s}$ for STS, a score $>46.5$ for BBS, a score $>25.5$ for FMA, a score $<13.5$ for FES, $>7.5 \mathrm{~kg}$ for dorsiflexor strength, $>30$ times for $2 \mathrm{mST}$, and $>318 \mathrm{~m}$ for $6 \mathrm{mWT}$. All clinical measures except FES had moderate accuracy according to the area under the curve of 0.76-0.88 (70-93\%). [Conclusion] Clinical measures (except FES) have moderate validity in predicting the level of community ambulation of stroke survivors. Key words: Stroke, Community ambulation, Predictive validity
\end{abstract}

(This article was submitted Feb. 2, 2016, and was accepted Apr. 25, 2016)

\section{INTRODUCTION}

Recovery of the gait ability of stroke survivors is an important goal of rehabilitation ${ }^{1)}$ and is known to be influenced by environmental factors (e.g., walking on the ground, climbing stairs, and avoiding obstacles), physical factors (e.g., muscle strength, endurance, and balance), and psychological factors (e.g., judgment, attention, stress, and fear of falls) ${ }^{2}$. Because several factors affect the gait ability of stroke survivors, assessing only a few factors is likely to limit the plan of care for gait recovery ${ }^{3)}$. Therefore, it is extremely important to assess the diverse range of factors influencing the gait ability of stroke survivors ${ }^{4)}$.

The methods commonly used in clinical settings to examine the gait ability of stroke survivors include the StepWatch Activity Monitor (SAM), Functional Ambulation Category (FAC), Dynamic Gait Index (DGI), gait scale in PerformanceOriented Mobility Assessment (POMA-gait), Wisconsin Gait Scale (WGS), 5- to 10-m walk test, 2-min step test, and 6-min walk test. However, it has been reported that these methods have limitations. Issues related to the validity of SAM hinder

*Corresponding author. Dong-sik Park (E-mail: don@hallym.or.kr)

(C)2016 The Society of Physical Therapy Science. Published by IPEC Inc.

This is an open-access article distributed under the terms of the Creative Commons Attribution Non-Commercial No Derivatives (by-nc-nd) License $<$ http://creativecommons.org/licenses/by-nc-nd/4.0/>. 
the proper assessment of gait levels ${ }^{5}$. Among stroke survivors who scored 4 points or more on FAC ${ }^{4,6)}$, which indicates the capability of independent gait without any extrinsic assistance, $32-47 \%$ were unable to perform community ambulation without extrinsic assistance ${ }^{4,7}$. In addition, DGI and POMA-gait were originally designed to predict falls by and the gait ability of the elderly, respectively ${ }^{8,9)}$. The WGS was found to have low inter-rater reliability and prone to learning effects because the method's accuracy relies on repeated measurements ${ }^{10}$. The 6-min walk test, which was devised to predict the level of community ambulation, has low discriminative power in comparison with the gait speed test and may be impractical for patients with significant declines in cardiopulmonary endurance.

In contrast, the gait speed test is simple compared to the walking distance test, and it can be used regardless of spatial constraints, thus placing lower psychological burden on the subjects ${ }^{11}$. Moreover, gait speed is reported to be better than walking distance at predicting the gait ability of stroke patients ${ }^{7,11-13)}$. As such, gait speed could serve as a predictor of the level of community ambulation of stroke survivors and as an objective indicator of their gait ability ${ }^{7}$ 14). However, few studies have investigated gait speed using tests or measures that are commonly used in clinical settings. Most of the tests or measures are used to determine intervention effects. According to previous studies, the following tests and measures are significantly associated with the level of community ambulation: the Sit to Stand test (STS) performed five times for evaluating muscle strength of the lower extremities; the Fugl-Meyer Assessment of lower extremities (FMA-LE) for evaluating motor function of the affected lower extremity; the Timed Up \& Go (TUG) test for evaluating mobility; the Berg Balance Scale (BBS) for evaluating the dynamic balance; the Falls Efficacy Scale (FES) for evaluating the fear of falls; and the walking distance test $^{11,15)}$. These tests and measures may help predict the gait speed for community ambulation. Thus, this study investigated the validity of clinical measures, such as dorsiflexor strength of the ankle joint, STS, TUG, BBS, FMA-LE, FES, and walking endurance tests, as predictors and discriminators of the level of community ambulation of hemiparetic stroke survivors.

\section{SUBJECTS AND METHODS}

For this study, stroke patients were recruited through advertisements at $\mathrm{M}$ rehabilitation center. The recruited volunteers were screened using the following criteria: more than 6 months since onset of chronic stroke; walking more than $10 \mathrm{~m}$ without assistive devices; no lower motor neuron injuries or musculoskeletal problems; and a score of least 24 on the MiniMental State Examination (MMSE). Patients with uncontrolled blood pressure, cardiac problems, pacemakers, or diabetes were excluded. Ninety-eight stroke patients were recruited and eight were excluded for not meeting the criteria. Ten subjects dropped out of the study (six subjects who were absentees, three subjects who were discharged, and one subject with a worsened condition). In addition, data of five subjects were missing or faulty. In total, the data of 75 subjects were analyzed. All participants provided their signed informed consent after receiving an explanation of the purpose and procedure of the study. The study was approved by Kyungnam University Institutional Review Board.

Information regarding gender, age, disease period, etiology, walking status (with or without assistive devices), and MMSE was collected from either medical charts or in brief interviews. Subjects were separated into two groups (community ambulation group $[>0.8 \mathrm{~m} / \mathrm{s}]$ or limited community ambulation group $[0.4-0.8 \mathrm{~m} / \mathrm{s}]$ ) based on the gait speed required for community ambulation during the $5-\mathrm{m}$ walk test reported in previous studies $(>0.8 \mathrm{~m} / \mathrm{s})^{7,13,16)}$. Then, tests and measures including dorsiflexor strength of the affected side, STS, TUG, BBS, FMA, FES, 2-min step test, and 6-min walk test were performed.

To examine the gait speed of the subjects, the $5-\mathrm{m}$ walk test was performed ${ }^{17)}$. This test has high test-retest reliability $(\mathrm{ICC}=0.88-0.97)^{18)}$. To examine dorsiflexor strength of the affected side, a hand dynamometer was used. The hand dynamometer is reported to be highly reliable $(\mathrm{ICC}=0.84-0.99)^{19,20)}$. STS was used to examine the muscle strength of the lower extremity. For this test, subjects repeatedly sat down and stood up five times ${ }^{21)}$. The inter-rater reliability of this test is high $(\mathrm{ICC}=0.87)^{22}$. TUG and BBS were used to examine functional mobility and balance. The test-retest reliability of TUG is high $(\mathrm{ICC}=0.96)^{18}$. Also, the test-retest reliability of BBS is excellent $(\mathrm{ICC}=0.98)^{23}{ }^{24}$. The motor function of the lower extremity on the affected side was examined using $\mathrm{FMA}^{25}$. The inter-rater and intra-rater reliabilities of FMA were reported as $r=0.94$ and $r=0.99$, respectively ${ }^{26}$. Fear of falling was examined with FES. FES consists of 13 items. Each item is rated using a score of $0-10(0=$ having no fear, $5=$ somewhat confident, $10=$ having much fear $)$. Higher scores indicate greater fear of falling or lower fall-related self-efficacy ${ }^{27}$. The 2-min step test and 6-min walk test were used to examine aerobic endurance. The 2-min step test measures the number of times that the lower extremities were lifted (one at a time if possible) up to the point halfway between the patella and the crista iliaca within $2 \min ^{28}$. The subjects were told to lift the affected lower extremity as high as the unaffected side ${ }^{14}$. In the 6-min walk test, the subjects were asked to repeatedly walk up and down a 20-m straight walkway for $6 \mathrm{~min}^{29)}$.

For the statistical analysis, SPSS version 16.0 was used. For the comparison of the two groups based on the level of community ambulation, the chi-square test or the independent t-test was used. To determine cutoff values of the tests and measures for predicting the level of community ambulation, the receiver-operating characteristic curve (ROC curve) was determined. To determine the accuracy of the tests and measures, the positive predictive value (PPV) and negative predictive value (NPV) were calculated. The area under the ROC curve (AUC) was divided into the following ranges: $0.5<\mathrm{AUC} \leq 0.7$ (less accurate); $0.7<\mathrm{AUC} \leq 0.9$ (moderately accurate); $0.9<\mathrm{AUC}<1$ (very accurate); and $\mathrm{AUC}=1$ (perfect) ${ }^{30}$. To determine the predictive validity of clinical measures for the level of community ambulation, a logistic regression analysis (forward Wald) was performed and odds ratios (OR) were calculated, with a cutoff value for each test or measure. The significance level was $\alpha=0.05$. 
Table 1. Characteristics of the subjects

\begin{tabular}{lccc}
\hline & Total $(\mathrm{n}=75)$ & $\begin{array}{c}\text { Community ambulation } \\
\text { group }(\mathrm{n}=33)\end{array}$ & $\begin{array}{c}\text { Limited community } \\
\text { ambulation group ( } \mathrm{n}=42)\end{array}$ \\
\hline Gender (M/F) & $40 / 35$ & $21 / 12$ & $19 / 23$ \\
Age (years) & $58.19 \pm 9.03$ & $56.27 \pm 7.02$ & $59.69 \pm 10.17$ \\
Disease duration (month) & $8.94 \pm 3.79$ & $9.78 \pm 5.19$ & $8.27 \pm 1.98$ \\
Etiology (infar./hemor.) & $47 / 28$ & $18 / 15$ & $29 / 13$ \\
Walking status (without-/with-) & $55 / 20$ & $26 / 7$ & $29 / 13$ \\
MMSE (score) & $26.45 \pm 2.00$ & $26.85 \pm 1.96$ & $26.14 \pm 2.00$ \\
5-m walk speed (m/s) & $0.85 \pm .21$ & $1.06 \pm .14$ & $0.69 \pm .06^{*}$ \\
Dorsiflexor strength (kg) & $6.93 \pm 2.64$ & $8.33 \pm 2.10$ & $5.83 \pm 2.52^{*}$ \\
STS (sec) & $12.60 \pm 4.24$ & $10.13 \pm 2.70$ & $14.54 \pm 4.26^{*}$ \\
TUG (sec) & $15.89 \pm 8.10$ & $10.97 \pm 3.87$ & $19.75 \pm 8.49^{*}$ \\
BBS (score) & $44.84 \pm 5.32$ & $47.82 \pm 4.22$ & $42.50 \pm 4.94^{*}$ \\
FMA (score) & $24.28 \pm 5.89$ & $28.61 \pm 4.50$ & $20.88 \pm 4.48^{*}$ \\
FES (score) & $18.27 \pm 12.17$ & $12.91 \pm 5.74$ & $22.48 \pm 14.15^{*}$ \\
\hline & Total (n=68) & Community ambulation & Limited community \\
& $29.09 \pm 15.21$ & group (n=33) & ambulation group (n=35) \\
\hline 2-min step test (frequency) & Total (n=66) & Community ambulation & Limited community \\
& & group (n=33) & ambulation group (n=33) \\
\hline 6-min walk test (meter) & $300.03 \pm 135.846$ & $377.45 \pm 113.78$ & $222.61 \pm 110.340^{*}$ \\
\hline *p<0.001. & & & \\
MMSE: Mini Mental State Examination; STS: Sit to Stand test; TUG: Timed Up \& Go test; BBS: Berg Balance Scale; &
\end{tabular}

\section{RESULTS}

There were no significant differences between the two groups in gender, age, disease duration, etiology, walking status, or MMSE; however, there were significant differences between the two groups regarding 5-m gait speed, dorsiflexor strength of the affected side, STS, TUG, BBS, FMA, FES, 2-min step test (7 out of 75 subjects failed the test), and 6-min walk test (9 out of 75 subjects failed the test) (Table 1).

For predicting the level of community ambulation (defined as gait speed $>0.8 \mathrm{~m} / \mathrm{s}$ ), the cutoff values of the test or measure were as follows: $>7.5 \mathrm{~kg}$ for the dorsiflexor strength of the affected side; $<12.6 \mathrm{~s}$ for STS; $<14.77 \mathrm{~s}$ for TUG; a score $>46.5$ for BBS; a score $>25.5$ for FMA; a score $<13.5$ for FES; $>30$ times for the 2-min step test; and $>332 \mathrm{~m}$ for the 6 -min walk test. The AUCs of all tests and measures were moderately accurate (0.76-0.88), except for FES, which was less accurate (0.68). PPVs were found for FMA (80\%), TUG (76\%), and 6-min walk test (76\%), whereas NPVs were found for TUG (89\%), BBS $(82 \%)$, FMA (82\%), STS (79\%), and 6-min walk test (78\%). The predictive values of FES (50-60\%) were relatively low compared to the other tests and measures (Table 2).

According to the logistic regression analysis that used the cutoff values of the tests and measures to predict the level of community ambulation, the following proved to have significant discriminative power: TUG $(<14.77 \mathrm{~s}$; OR $=0.038)$; FMA $(>25.5 ; \mathrm{OR}=0.053) ; 6$-min walk test $(>332 \mathrm{~m} ; \mathrm{OR}=0.086) ; \mathrm{BBS}(>46.5 ; \mathrm{OR}=0.084) ; \mathrm{STS}(<12.6 \mathrm{~s} ; \mathrm{OR}=0.114) ; 2-\mathrm{min}$ step test $(>30$ times,; OR=0.150); and dorsiflexor strength of the affected side $(>7.5 \mathrm{~kg}$; OR=0.179). However, no significant discriminative power was found for FES (Table 3).

\section{DISCUSSION}

The present study showed that dorsiflexor strength of the affected side, STS, TUG, BBS, FMA, 2-min step length test, and 6-min walk test may have sufficient discriminative power to predict the level of community ambulation, but that FES does not. In addition, all the tests and measures except FES were moderately accurate, with the AUC ranging from 0.72 to 0.88 .

TUG involves performing daily living activities, such as rising from a chair, turning $180^{\circ}$, walking, and sitting in a chair. Thus, these might be reflected in the level of community ambulation. In this study, the cutoff value for TUG was $<14.77 \mathrm{~s}$, which is close to that reported by a previous study in which it took $16.7 \mathrm{~s}$ for community-dwelling stroke survivors to perform $\mathrm{TUG}^{31)}$. The cutoff value of STS for predicting the level of community ambulation was $12.6 \mathrm{~s}$ in this study. Mong et al. used a cutoff value of $12 \mathrm{~s}$ for STS to distinguish community-dwelling healthy elderly individuals from chronic stroke survivors, 
Table 2. Cutoff value, AUC, sensitivity, specificity, positive predictive value, and negative predictive value for predicting of level community ambulation

\begin{tabular}{|c|c|c|c|c|c|c|c|}
\hline & $\mathrm{n}$ & Cutoff value & AUC & Sensitivity & Specificity & $\begin{array}{l}\text { Positive } \\
\text { Predictive } \\
\text { Value }\end{array}$ & $\begin{array}{c}\text { Negative } \\
\text { Predictive } \\
\text { Value }\end{array}$ \\
\hline $\begin{array}{l}\text { Dorsiflexor } \\
\text { strength }\end{array}$ & 75 & $>7.5(\mathrm{~kg})$ & $0.76^{* *}(0.67-0.88)$ & $21 / 33(64 \%)$ & $32 / 42(76 \%)$ & $21 / 31(68 \%)$ & $32 / 44(73 \%)$ \\
\hline STS & 75 & $<12.6(\mathrm{sec})$ & $0.80 * *(0.71-0.90)$ & $25 / 33(76 \%)$ & $31 / 42(70 \%)$ & $25 / 36(69 \%)$ & $31 / 39(79 \%)$ \\
\hline TUG & 75 & $<14.77$ (sec) & $0.88^{* *}(0.80-0.96)$ & $29 / 33(88 \%)$ & $33 / 42(79 \%)$ & $29 / 38(76 \%)$ & $33 / 37(89 \%)$ \\
\hline BBS & 75 & $>46.5$ (score) & $0.79 * *(0.69-0.89)$ & $26 / 33(79 \%)$ & $32 / 42(76 \%)$ & $26 / 36(72 \%)$ & $32 / 39(82 \%)$ \\
\hline FMA & 75 & $>25.5$ (score) & $0.87 * *(0.79-0.96)$ & $25 / 33(76 \%)$ & $36 / 42(86 \%)$ & $25 / 31(80 \%)$ & $36 / 44(82 \%)$ \\
\hline FES & 75 & $<13.5$ (score) & $0.68^{* *}(0.56-0.80)$ & $16 / 33(50 \%)$ & $25 / 42(56 \%)$ & $16 / 33(55 \%)$ & $25 / 42(60 \%)$ \\
\hline 2-min step test & 68 & $>30$ (frequency) & $0.81 * *(0.70-0.92)$ & $24 / 33(73 \%)$ & $25 / 35(71 \%)$ & $24 / 34(71 \%)$ & $25 / 34(74 \%)$ \\
\hline 6 -min walk test & 66 & $>332$ (meter) & $0.82 * *(0.72-0.93)$ & $26 / 33(78 \%)$ & $25 / 33(75 \%)$ & $26 / 34(76 \%)$ & $25 / 32(78 \%)$ \\
\hline
\end{tabular}

AUC: area under the ROC curve; STS: Sit to Stand test; TUG: Timed Up \& Go test; BBS: Berg Balance Scale; FMA: Fugl-Meyer Assessment; FES: Falls Efficacy Scale

$* * \mathrm{p}<0.001$

Table 3. Odds ratios of tests or measures for predicting the level of community ambulation

\begin{tabular}{lccccc}
\hline & $\mathrm{n}$ & $\begin{array}{c}\text { Regression } \\
\text { coefficient }\end{array}$ & $\begin{array}{c}\text { Standard } \\
\text { error }\end{array}$ & Odds ratio & $\begin{array}{c}95 \% \text { confidence } \\
\text { interval }\end{array}$ \\
\hline TUG $<14.77$ (sec) & 75 & $-3.280^{*}$ & 0.653 & 0.038 & $0.010-0.135$ \\
FMA $>25.5$ (score) & 75 & $-2.931^{*}$ & 0.600 & 0.053 & $0.016-0.173$ \\
6-min walk test $>332$ (meter) & 66 & $-2.452^{*}$ & 0.588 & 0.086 & $0.027-0.273$ \\
BBS $>46.5$ (score) & 75 & $-2.475^{*}$ & 0.559 & 0.084 & $0.028-0.252$ \\
STS $<12.6$ (sec) & 75 & $-2.176^{*}$ & 0.537 & 0.114 & $0.040-0.325$ \\
2-min step test $>30$ (frequency) & 68 & $-1.897^{*}$ & 0.541 & 0.150 & $0.052-0.433$ \\
Dorsiflexor strength $>7.5(\mathrm{~kg})$ & 75 & $-1.723^{*}$ & 0.512 & 0.179 & $0.065-0.487$ \\
FES $<13.5$ (score) & 75 & - & - & - & - \\
\hline
\end{tabular}

${ }^{*} \mathrm{p}<0.001$.

Independent variables: cutoff values of tests or measurements

Dependent variables: $0=$ Community ambulation group $(>0.8 \mathrm{~m} / \mathrm{s}) ; 1=$ Limited community ambulation group $(0.4-0.8 \mathrm{~m} / \mathrm{s})$

STS: Sit to Stand test; TUG: Timed Up \& Go test; BBS: Berg Balance Scale; FMA: Fugl-Meyer Assessment; FES: Falls Efficacy Scale

and they used $9.4 \mathrm{~s}$ as the cutoff value for distinguishing healthy elderly individuals from young adults ${ }^{23}$. In addition, the cutoff values for BBS and FMA for predicting the level of community ambulation were scores of 46.5 and 25.5 , respectively, which are comparable to a previous study that reported a BBS cutoff score of 49.3 and a FMA cutoff score of 28.7 for stroke survivors capable of community ambulation ${ }^{5}$. Hsu et al. found that gait speed $(0.95 \mathrm{~m} / \mathrm{s})$ and FMA (28) were significantly correlated $(r=0.48)^{32}$. In this study, the gait speed and FMA score of stroke survivors capable of community ambulation were $1.06 \mathrm{~m} / \mathrm{s}$ and 28.61 , respectively. These results are consistent with those reported by $\mathrm{Ng}$ et al. $(1.0 \mathrm{~m} / \mathrm{s} \text { and } 26 \text {, respectively })^{17)}$. A previous study reported that the dorsiflexor strength of the affected side of stroke survivors is influenced by STS, gait speed ( $r=0.67$, explanatory power: $30 \%, r=0.73$ ), and walking distance $(r=0.79,48.8 \%)^{17)}$. Although no cutoff value was reported for the dorsiflexor strength of the affected side in that study, the cutoff value in this study was $>7.5 \mathrm{~kg}$, which is comparable to the cutoff value of $6.1 \mathrm{~kg}$ reported by Mong et $\mathrm{al}^{23)}$. However, Mong et al. reported $17.1 \mathrm{~s}$ for STS, which differs from the results of this study by approximately $4.5 \mathrm{~s}^{23}$. In the 2-min step test, given that the standard values for healthy subjects (age 65-74 years) are 65-116 times, the standard value for stroke survivors with neurological problems should be $80 \%{ }^{14)}$ or at least 52 times. Nevertheless, the cutoff value of the 2-min step test for predicting the level of community ambulation ability was 30 times $(46 \%)$ in this study. These findings were significantly lower that those reported by a previous study, a gait speed of $0.75 \mathrm{~m} / \mathrm{s}$ for predicting the level of community ambulation, and 39.7 times in the 2-min step test, or $61 \%$ of performance levels of healthy adults ${ }^{14)}$. Moreover, the cutoff distances of the 6-min walk test for predicting the level of community ambulation have been reported as $348.6 \mathrm{~m}^{5}$ ) and $367.5 \mathrm{~m}^{11)}$, slightly longer than the cutoff value of $332 \mathrm{~m}$ in this study. The disparity appears to be attributable to the lower gait speed $(0.85 \mathrm{~m} / \mathrm{s})$ of the subjects in this study compared with those of the 
subjects in previous studies $(1.0-1.01 \mathrm{~m} / \mathrm{s})$.

Taken together, except for FES, the tests and measures, such as dorsiflexor strength of the affected side, STS for muscle strength of the lower extremity, TUG for functional mobility, BBS for dynamic balance, FMA for motor function of the lower extremity, the 2-min step test for aerobic endurance, and the 6-min walk test for walking distance, were shown to have discriminative power for predicting the level of community ambulation. However, these tests or measures were performed at certain points in time, which could limit their applicability to all other patients, particularly to those who cannot perform long-distance walking despite having high gait speed, or vice versa. Therefore, more extensive studies are needed.

\section{REFERENCES}

1) Shim S, Yu J, Jung J, et al.: Effects of motor dual task training on spatiotemporal gait parameters of post-stroke patients. J Phys Ther Sci, 2012 , 24: 845-848. [CrossRef]

2) Hong E: Comparison of quality of life according to community walking in stroke patients. J Phys Ther Sci, 2015, 27: 2391-2393. [Medline] [CrossRef]

3) Fisher AG, Short-DeGraff M: Improving functional assessment in occupational therapy: recommendations and philosophy for change. Am J Occup Ther, 1993, 47: 199-201. [Medline] [CrossRef]

4) Lord SE, McPherson K, McNaughton HK, et al.: Community ambulation after stroke: how important and obtainable is it and what measures appear predictive? Arch Phys Med Rehabil, 2004, 85: 234-239. [Medline] [CrossRef]

5) Fulk GD, Reynolds C, Mondal S, et al.: Predicting home and community walking activity in people with stroke. Arch Phys Med Rehabil, 2010, 91: 1582-1586. [Medline] [CrossRef]

6) Veerbeek JM, Van Wegen EE, Harmeling-Van der Wel BC, et al. EPOS Investigators: Is accurate prediction of gait in nonambulatory stroke patients possible within 72 hours poststroke? The EPOS study. Neurorehabil Neural Repair, 2011, 25: 268-274. [Medline] [CrossRef]

7) Nagano K, Hori H, Muramatsu K: A comparison of at-home walking and 10-meter walking test parameters of individuals with post-stroke hemiparesis. J Phys Ther Sci, 2015, 27: 357-359. [Medline] [CrossRef]

8) Schumway-Cook A, Woollacott M: Motor control: theory and practical applications. Baltimore: Williams \& Wilkins, 1995.

9) Tinetti ME: Performance-oriented assessment of mobility problems in elderly patients. J Am Geriatr Soc, 1986, 34: 119-126. [Medline] [CrossRef]

10) Rodriquez AA, Black PO, Kile KA, et al.: Gait training efficacy using a home-based practice model in chronic hemiplegia. Arch Phys Med Rehabil, 1996, 77 : 801-805. [Medline] [CrossRef]

11) Bijleveld-Uitman M, van de Port I, Kwakkel G: Is gait speed or walking distance a better predictor for community walking after stroke? J Rehabil Med, 2013, 45: 535-540. [Medline] [CrossRef]

12) Hill K, Ellis P, Bernhardt J, et al.: Balance and mobility outcomes for stroke patients: a comprehensive audit. Aust J Physiother, 1997, 43: 173-180. [Medline] [CrossRef]

13) van de Port IG, Kwakkel G, Lindeman E: Community ambulation in patients with chronic stroke: how is it related to gait speed? J Rehabil Med, 2008, 40: 23-27. [Medline] [CrossRef]

14) Taylor-Piliae RE, Latt LD, Hepworth JT, et al.: Predictors of gait velocity among community-dwelling stroke survivors. Gait Posture, 2012, 35: 395-399. [Medline] [CrossRef]

15) Ng SS, Hui-Chan CW: The timed up \& go test: its reliability and association with lower-limb impairments and locomotor capacities in people with chronic stroke. Arch Phys Med Rehabil, 2005, 86: 1641-1647. [Medline] [CrossRef]

16) Taylor D, Stretton CM, Mudge S, et al.: Does clinic-measured gait speed differ from gait speed measured in the community in people with stroke? Clin Rehabil, 2006, 20: 438-444. [Medline] [CrossRef]

17) Ng SS, Ng PC, Lee CY, et al.: Walkway lengths for measuring walking speed in stroke rehabilitation. J Rehabil Med, 2012, 44: 43-46. [Medline] [CrossRef]

18) Flansbjer UB, Holmbäck AM, Downham D, et al.: Reliability of gait performance tests in men and women with hemiparesis after stroke. J Rehabil Med, 2005, 37: 75-82. [Medline] [CrossRef]

19) Bohannon RW: Test-retest reliability of hand-held dynamometry during a single session of strength assessment. Phys Ther, 1986, 66: 206-209. [Medline]

20) Bohannon RW, Andrews AW: Interrater reliability of hand-held dynamometry. Phys Ther, 1987, 67: 931-933. [Medline]

21) Mong Y, Teo TW, Ng SS: 5-repetition sit-to-stand test in subjects with chronic stroke: reliability and validity. Arch Phys Med Rehabil, $2010,91: 407-413$. [Medline] [CrossRef]

22) Lord SR, Murray SM, Chapman K, et al.: Sit-to-stand performance depends on sensation, speed, balance, and psychological status in addition to strength in older people. J Gerontol A Biol Sci Med Sci, 2002, 57: M539-M543. [Medline] [CrossRef]

23) Berg K: Balance and its measure in the elderly: a review. Physiother Can, 1989, 41: 240-246. [CrossRef]

24) Liston RA, Brouwer BJ: Reliability and validity of measures obtained from stroke patients using the Balance Master. Arch Phys Med Rehabil, 1996, 77: 425-430. [Medline] [CrossRef]

25) Park EY, Choi YI: Psychometric properties of the lower extremity subscale of the Fugl-Myer assessment for community-dwelling hemiplegic stroke patients. J Phys Ther Sci, 2014, 26: 1775-1777. [Medline] [CrossRef]

26) Duncan PW, Propst M, Nelson SG: Reliability of the Fugl-Meyer assessment of sensorimotor recovery following cerebrovascular accident. Phys Ther, 1983, 63: 1606-1610. [Medline]

27) Fletcher PC, Hirdes JP: Restriction in activity associated with fear of falling among community-based seniors using home care services. Age Ageing, 2004, 33: 273-279. [Medline] [CrossRef]

28) Rikli RE, Jones CJ: Development and validation of criterion-referenced clinically relevant fitness standards for maintaining physical independence in later years. Gerontologist, 2013, 53: 255-267. [Medline] [CrossRef]

29) Caballer VB, Lisón JF, Rosado-Calatayud P, et al.: Factors associated with the 6-minute walk test in nursing home residents and community-dwelling older 
adults. J Phys Ther Sci, 2015, 27: 3571-3578. [Medline] [CrossRef]

30) Lee G, An S, Lee Y, et al.: Predictive factors of hypertonia in the upper extremity of chronic stroke survivors. J Phys Ther Sci, 2015, 27: 2545-2549. [Medline] [CrossRef]

31) Knorr S, Brouwer B, Garland SJ: Validity of the community balance and mobility scale in community-dwelling persons after stroke. Arch Phys Med Rehabil, 2010, 91: 890-896. [Medline] [CrossRef]

32) Hsu AL, Tang PF, Jan MH: Analysis of impairments influencing gait velocity and asymmetry of hemiplegic patients after mild to moderate stroke. Arch Phys Med Rehabil, 2003, 84: 1185-1193. [Medline] [CrossRef] 